\title{
Percutaneous Pharmaco-Mechanical Thrombectomy of Acute Symptomatic Superior Mesenteric Vein Thrombosis
}

\author{
Paolo Rabuffi ${ }^{1}$ - Simone Vagnarelli $^{1}$ - Antonio Bruni ${ }^{1} \cdot$ Gabriele Antonuccioo $^{1}$. \\ Cesare Ambrogi ${ }^{1}$
}

Received: 12 June 2019/Accepted: 3 October 2019/Published online: 24 October 2019

(C) The Author(s) 2019

\begin{abstract}
Purpose To evaluate the safety and the efficacy of percutaneous pharmaco-mechanical thrombectomy (PPMT) of acute superior mesenteric vein (SMV) thrombosis.

Methods A database of patients treated between 2011 and 2018 with acute venous mesenteric ischemia (VMI) was reviewed. VMI was diagnosed in the presence of SMV thrombosis and CT evidence of jejunal thickening. All patients presented with mild to moderate peritonism, which allowed surgery to be postponed. Initial treatment consisted of heparinization. PPMT was indicated in case of worsening abdominal pain despite anticoagulation and was performed via a transjugular or transhepatic approach, using a rotational aspiration thrombectomy catheter, followed by transcatheter thrombolysis. Clinical success was defined as symptoms resolution. Technical success was defined as patency of $>50 \%$ of SMV at venography and resolution of jejunal thickening. Patients were discharged on lifelong oral anticoagulation (INR 2.5-3.5). Follow-ups were performed using CT and color Doppler ultrasound.
\end{abstract}

Paolo Rabuffi

paolorabuffi@gmail.com

Simone Vagnarelli

simone.vagnarelli@tin.it

Antonio Bruni

tonino.bruni@fastwebnet.it

Gabriele Antonuccio

dr.gabrieleantonuccio@gmail.com

Cesare Ambrogi

cambrogivasc@yahoo.it

1 Department of Interventional Radiology, “San Giovanni Addolorata" Hospital, Via dell'Amba Aradam 9, 00184 Rome, Italy
Results Population consisted of eight males, aged 37-81 (mean 56.5 years). Causes for thrombosis were investigated. Urokinase infusion time ranged from 48 to $72 \mathrm{~h}$ (3,840,000-5,760,000 IU). Clinical and technical success was obtained in all cases. One patient experienced bleeding from the superior epigastric artery and was treated with embolization. One patient died of multi-organ failure after 35 days, despite resolution of SMV thrombosis. In no case was surgery required after PPMT; mean hospitalization was 14.1 days (9-24). Mean follow-up of remaining seven patients was 37.7 months (12-84 months).

Conclusion PPMT of acute SMV thrombosis seems safe and effective, with an $87.5 \%$ long-term survival rate and a $12.5 \%$ major complication rate.

Keywords Acute superior mesenteric vein thrombosis - Mesenteric venous ischemia . Percutaneous mechanical thrombectomy $\cdot$ Pharmacomechanical thrombectomy · Transcatheter thrombolysis · Aspirex

\section{Introduction}

Acute SMV thrombosis is a rare disease that accounts for $5-15 \%$ of mesenteric thromboembolic events [1]. Owing to a delay in diagnosis determined by its vague symptomatological profile, it is associated with high rates of mortality, up to $50 \%$ in the case of intestinal infarction [2]. The causes of acute SMV thrombosis include liver cirrhosis, a previous history of surgery, abdominal infection or inflammation, and hypercoagulable states (such as deficiencies of antithrombin III, protein $\mathrm{C}$, protein $\mathrm{S}$, and factor V Leiden) [3]. Systemic anticoagulation with heparin is the initial conventional therapy for acute SMV thrombosis. 
Surgery is indicated in the presence of clinically severe peritonism, or in the case of bowel infarction or perforation at CT, but it is burdened with high mortality (up to $39 \%$ ) and morbidity (32-71\%) rates [4]. In recent years, endovascular treatment options such as transcatheter thrombolysis and percutaneous mechanical thrombectomy have been increasingly used in cases of acute SMV thrombosis in order to achieve early revascularization [5] and have been shown to lower mortality rates, reduce hospitalization stays, and diminish the impact of surgical resection [6].

The aim of this retrospective series is to investigate the safety and efficacy of percutaneous pharmaco-mechanical thrombectomy in the treatment of symptomatic acute SMV thrombosis with the use of the Aspirex thrombectomy device (Straub Medical, Wangs, Switzerland), followed by local thrombolysis.

\section{Methods}

The database of patients admitted to our department for acute abdominal pain (symptom onset $<14$ days), caused by acute SMV thrombosis, who underwent PPMT between 2011 and 2018, was reviewed. Venous mesenteric ischemia was diagnosed in the presence of SMV thrombosis, associated with the evidence of circumferential wall thickening and congestion of the jejunum loop without signs of pneumatosis or pneumoperitoneum at CT. All patients presented with mild to moderate clinical signs of peritonism, which allowed the surgery to be postponed. Initial treatment consisted of systemic heparinization through intravenous administration of unfractionated heparin adjusted to keep aPTT two times control. Treatment by PPMT was indicated in those cases where the intensity of abdominal pain increased, despite having received promptly initiated medical therapy. Informed consent was obtained from all patients. Contraindications to thrombolysis consisted of previous strokes, brain malignancies, coagulopathy, recent gastrointestinal hemorrhage, or active bleeding diathesis.

\section{Thrombectomy and Thrombolysis Technique}

The portal vein was accessed through a percutaneous USguided transhepatic approach, using a 21-G Chiba needle and an Accustick system (Boston Scientific, Natick, MA, USA) or through the creation of a TIPS with a Viatorr stent-graft (Gore, Flagstaff, AZ, USA). Regardless of the approach used, after accessing the portal system, a guide wire was advanced distally and a 10-Fr Aspirex device was put into place. Aspirex is a wall-contact thrombus aspiration system that works through a suction action produced by a slit situated in the distal tip of the catheter, combined with the fragmentation of the aspired clot through a rotating stainless steel spiral located in the catheter lumen. After execution of mechanical thrombectomy in the main trunk of SMV and in the portal vein when needed, occluded SMV side branches were treated via selective aspiration thrombectomy through a 7-Fr guide catheter connected to a Penumbra pump (Alameda, California, USA). At this point, a venogram was obtained, and when a partial recanalization of the SMV was observed, a side-hole infusion catheter was put into place to perform local thrombolysis for the following 18-24 h. If thrombosis persisted without signs of recanalization, a new session of mechanical thrombectomy with Aspirex was immediately repeated. Urokinase was the thrombolytic agent of choice, at the dosage of 80,000-100,000 IU per hour, based on the patient's weight. Following the mechanical thrombectomy session, for the entire duration of the thrombolysis infusion, patients were transferred to the intensive care unit; blood coagulation and fibrinogen were strictly monitored and UK dosage adjusted consequently. Venographic evaluation was performed the following day, and a thrombectomy session was repeated if a significant amount of residual thrombus within the SMV was still present at the control. Transcatheter thrombolysis was interrupted when a patency of at least $50 \%$ of the SMV was observed with restoration of an antegrade flow to the portal system. Tract embolization was performed in all cases of transhepatic approach using Onyx 34.

\section{Endpoints and Follow-Up}

Clinical success was defined as the resolution of symptoms. Technical success was defined as $>50 \%$ patency of the previously thrombosed vessel, with restoration of antegrade filling of SMV branches confirmed by venography at the conclusion of the treatment, and resolution of bowel wall thickening at CT.

After the procedure, all patients were discharged on lifelong oral anticoagulation therapy (INR 2.5-3.5). Follow-ups were performed using CT at the moment of discharge, after 1 month, and then 1 year after treatment. Color Doppler ultrasound follow-ups were performed at 3 and 6 months after treatment, and subsequently yearly.

\section{Results}

The study population consisted of eight males, aged 37-81 (mean 56.5 years). All patients complained of severe abdominal pain; two patients were also suffering from nausea and three from abdominal distension. CT was repeated after completion of the treatment in order to assess bowel wall status and confirm venous patency. Etiology 
and causes of thrombosis were investigated in all patients (see Table 1). There were no contraindications to thrombolysis. Urokinase infusions ranged from a minimum period of $48 \mathrm{~h}$ to a maximum of $72 \mathrm{~h}$, with dosages ranging from $3,840,000$ to $5,760,000$ IU. Acute SMV thrombosis was associated with portal vein thrombosis in seven out of eight cases. Different grades of portal thrombosis involvement were observed: in six cases, both the main portal trunk and the intrahepatic portal branches were affected, while in one case the right portal branch and the main portal trunk were involved. In all the cases of extensive portomesenteric thrombosis, a cavernomatous transformation was already present at the initial CT. The splenic vein was also affected in three out of seven patients, with CT findings of asymptomatic partial splenic infarction in one case.

In five out of eight patients, a right portal branch was punctured using a transjugular (TJ) approach and a portosystemic shunt (TIPS) was created in order to access the SMV and perform thrombectomy. In three out of five cases, a TIPS was created by targeting a landing site on a thrombosed portal branch because of a coexisting intraand extrahepatic portal vein thrombosis. In the remaining three patients, a transhepatic ultrasound-guided approach was preferred. Clinical and technical success was obtained in all cases and coincided with flow restoration in the SMV. SMV remained patent at all follow-up controls in all cases. There were two cases of early portal rethrombosis with the evidence of cavernomatosis at the end of the treatment, despite successful intraoperative recanalization after PPMT. In these cases, the final venography showed good outflow from the restored SMV to the intrahepatic portal branches, or to the TIPS via the cavernomatosis. Portal vein thrombosis reoccurred postoperatively in three cases, at 1-month FU. TIPS patency was confirmed at dismissal, but during follow-up, shunt obstruction was detected in three out of four cases, respectively, at 1-, 6- and 12-month FU, despite anticoagulation therapy. In these patients, SMV was patent at every FU control and flow to the portal intrahepatic branches was ensured via the cavernomatosis. Neither explorative nor resective surgery was required after PPMT; mean hospitalization stay was 19.4 days (9-38). Mean follow-up (in remaining seven patients) after discharge was 37.7 months (12-84 months).

\section{Complications}

One patient developed an abdominal wall hematoma after $48 \mathrm{~h}$ of local thrombolysis and underwent CT, which revealed the presence of active bleeding fed from the superior left epigastric artery. Thrombolysis was suspended, and the bleeding was successfully treated via a transfemoral catheterization and a superselective embolization with Onyx.

One patient died of multi-organ failure (MOF) 35 days after treatment. This patient had initially undergone surgery because of bowel necrosis present at the onset with severe peritonism, sustained by portomesenteric thrombosis. However, 3 days after resection, there was a recurrence of mesenteric ischemia due to a distal extension of the SMV thrombosis. In order to avoid surgical reintervention, PPMT was performed via a TIPS creation because of the presence of an extensive portomesenteric thrombosis. After $48 \mathrm{~h}$ of thrombolysis, complete symptom resolution was obtained. After 6 days of well-being, the patient developed a fever caused by fluid collection. A drainage was put into place, and the patient was put on antibiotic therapy. After 18 days, despite resolution of the collection, MOF occurred and the patient died (Table 2).

Table 1 Patients demographics, clinical presentation, etiology, and comorbidities

\begin{tabular}{llllll}
\hline Pt. no. & Age (years) & Sex & Symptoms & Etiology & Comorbidities \\
\hline 1 & 61 & M & Abdominal pain & Antiphospholipid antibody syndrome & $\begin{array}{l}\text { Chronic hepatopathy } \\
\text { Crohn's disease }\end{array}$ \\
2 & 69 & M & Abdominal pain & Unknown & Chronic hepatopathy \\
3 & 81 & M & Abdominal pain & Unknown & Chronic hepatopathy \\
4 & 55 & M & Abdominal pain & Unknown & None \\
5 & 44 & & Nausea & & Crohn's disease \\
6 & 37 & M & Abdominal pain & Unknown & Chronic hepatopathy \\
7 & 59 & $\mathrm{M}$ & Abdominal pain & Unknown & Cirrhosis \\
8 & 46 & $\mathrm{M}$ & Abdominal pain & Unknown & Myeloproliferative disease \\
\hline
\end{tabular}




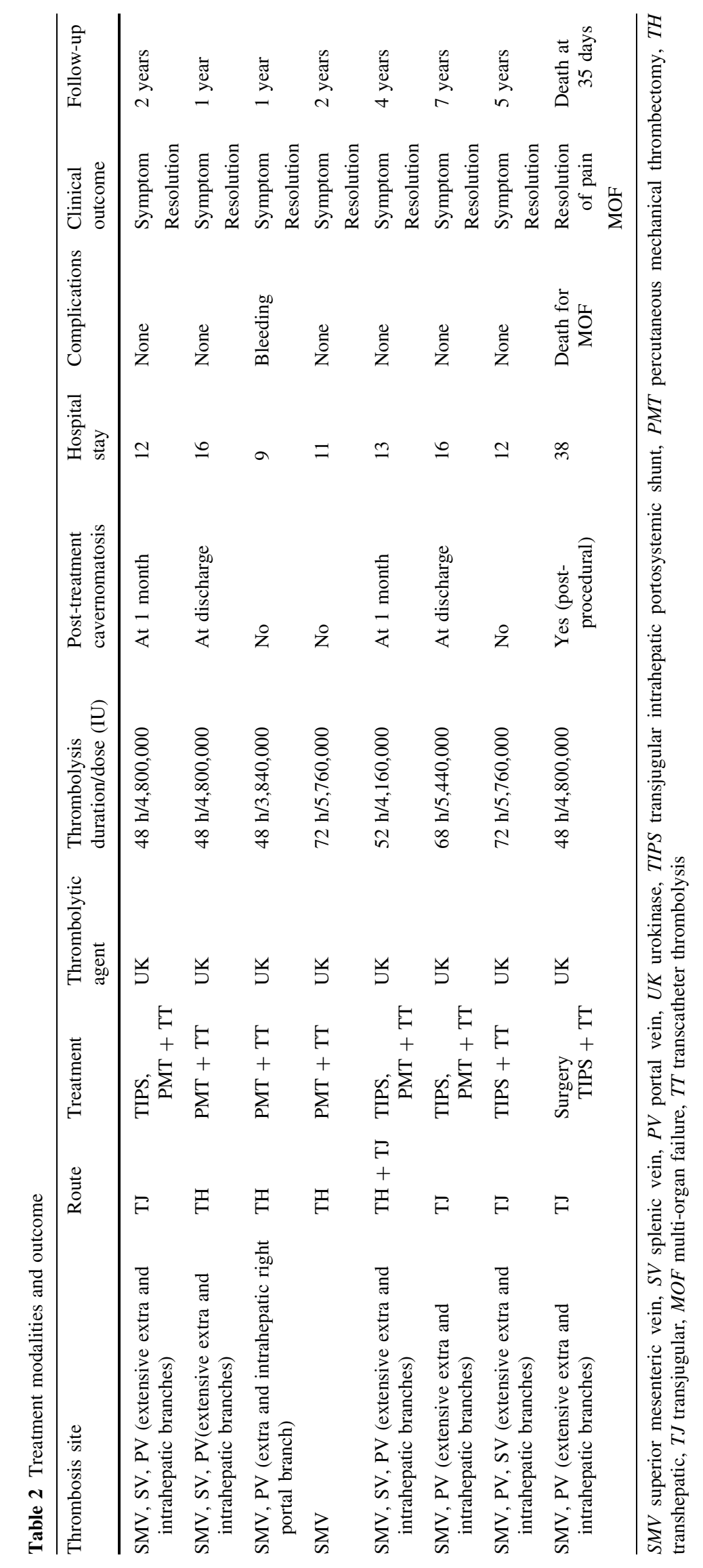


Table 3 Previously published studies

\begin{tabular}{|c|c|c|c|c|c|c|c|c|}
\hline $\begin{array}{l}\text { Author } \\
\text { (year) }\end{array}$ & Patients & $\begin{array}{l}\text { Thrombectomy } \\
\text { device }\end{array}$ & Route & $\begin{array}{l}\text { Thrombolytic } \\
\text { agent }\end{array}$ & Dose-duration & $\begin{array}{l}\text { Clinical } \\
\text { outcome }\end{array}$ & $\begin{array}{l}\text { Surgical } \\
\text { resection }\end{array}$ & Complications \\
\hline $\begin{array}{l}\text { Rosen, } \\
\text { (2000) }\end{array}$ & 1 & Angiojet & $\mathrm{TH}+\mathrm{TA}$ & - & - & Successful & No & - \\
\hline $\begin{array}{l}\text { Lopera } \\
\text { (2002) }\end{array}$ & 2 & $\begin{array}{l}\text { Oasis, arrow- } \\
\text { Trerotola }\end{array}$ & TH & Urokinase & $12 \mathrm{~h}-100,000 \mathrm{IU} / \mathrm{h}$ & Successful & No & - \\
\hline Kim (2005) & 7 & $\begin{array}{l}\text { Angiojet, } \\
\text { Amplatz }\end{array}$ & $\mathrm{TH}$ & $\begin{array}{l}\text { rt-PA } \\
\text { Urokinase }\end{array}$ & $\begin{array}{l}\text { Up to } 45 \mathrm{~h} \\
\text { Up to } 8.5 \text { million } \\
\text { IU }\end{array}$ & $\begin{array}{l}6 \text { Successful } \\
1 \text { unsuccessful }\end{array}$ & No & $\begin{array}{l}1 \text { Hemothorax } \\
1 \text { death }\end{array}$ \\
\hline $\begin{array}{l}\text { Takahashi } \\
\text { (2005) }\end{array}$ & 1 & Oasis & $\mathrm{TH}$ & Urokinase & $\begin{array}{l}72 \mathrm{~h}- \\
240,000 \mathrm{IU} / \mathrm{day}\end{array}$ & Successful & Yes & - \\
\hline Zhou (2007) & 2 & Angiojet & $\mathrm{TH}$ & rt-PA & $12 \mathrm{~h}$ & Successful & No & - \\
\hline $\begin{array}{l}\text { Wasselius } \\
\text { (2014) }\end{array}$ & 1 & Angiojet & $\begin{array}{l}\mathrm{TJ}+\mathrm{TIPS} \\
\quad+\mathrm{TA}\end{array}$ & rt-PA & $33 \mathrm{~h}$ & Successful & No & - \\
\hline Jun (2014) & 2 & Angiojet & TH & Urokinase & $48 \mathrm{~h}-100,000 \mathrm{IU} / \mathrm{h}$ & Successful & No & - \\
\hline $\begin{array}{l}\text { Lorenz } \\
\qquad(2014)\end{array}$ & 1 & Trellis & $\mathrm{TJ}$ & rt-PA & $12 \mathrm{~h}$ & Successful & No & $\begin{array}{l}1 \text { Bleeding } \\
\text { requiring } \\
\text { transfusions }\end{array}$ \\
\hline Song (2017) & 8 & Angiojet & $\mathrm{TH}$ & Urokinase & $\begin{array}{l}24-48 \mathrm{~h} \text { to } \\
500,000 \mathrm{IU} / \mathrm{day}\end{array}$ & Successful & No & $\begin{array}{l}1 \text { Bleeding } \\
\text { requiring } \\
\text { transfusions }\end{array}$ \\
\hline Syed (2018) & 2 & Angiojet & $\mathrm{TH}$ & rt-PA & - & Successful & No & - \\
\hline $\begin{array}{r}\text { Kuetting } \\
(2018)\end{array}$ & 3 & Angiojet & TIPS & Urokinase & $\begin{array}{l}22-52 \mathrm{~h} \text { to } \\
100,000 \mathrm{IU} / \mathrm{h}\end{array}$ & $\begin{array}{l}\text { Successful in } 2 / 3 \\
\text { cases }\end{array}$ & No & 2 Hematuria \\
\hline
\end{tabular}

$U K$ urokinase, $r t-P A$ recombinant tissue plasminogen activator, $T A$ transarterial, $T H$ transhepatic, $T J$ transjugular
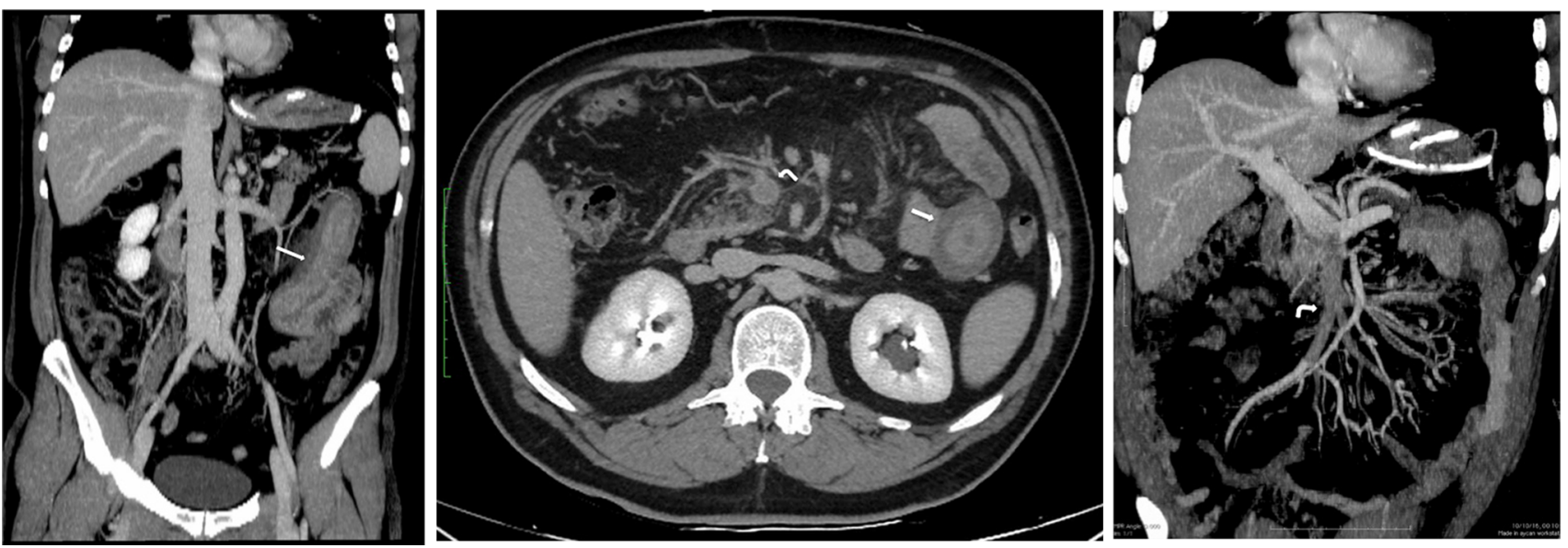

Fig. 1A, B, 2 Preoperative contrast-enhanced CT scans of a 55-year-old male (patient No. 4) show thickening of jejunum loop (arrow) and extensive thrombosis of the SMV (curved arrow)

\section{Discussion}

Although to date there is no consensus on treatment of acute SMV thrombosis, once it has been diagnosed, the primary goal of therapy must be to avoid the process leading to transmural infarction, perforation, and severe peritonitis. Systemic heparinization may improve recanalization rates up to $80 \%$ [7] and can be beneficial in terms of patient survival [8]. However, anticoagulation alone is associated with recurrence of thrombotic events in 3-40\% of cases [9].

Surgery is mandatory in the presence of severe peritonitis or perforation [5], but even when the diagnosis is established promptly, 30-day mortality rates in acute SMV thrombosis range from 13 to $50 \%$ with traditional treatment of anticoagulation and bowel resection [10]. However, 


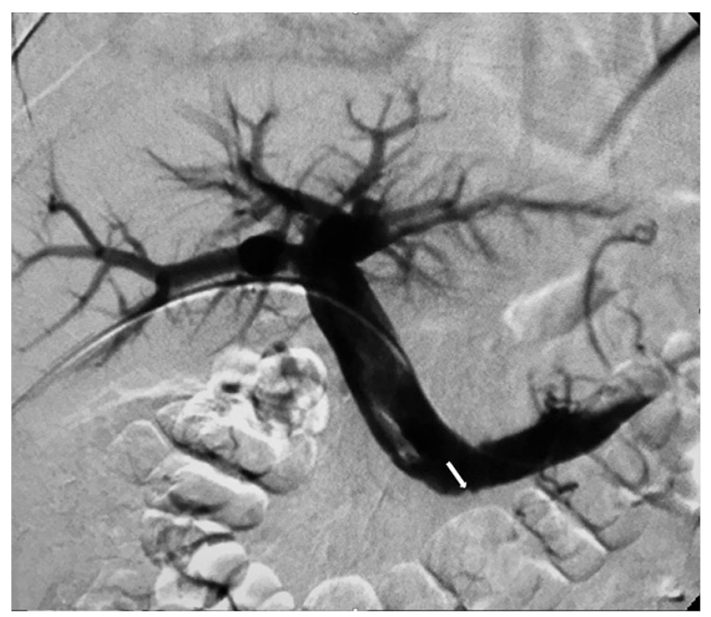

Fig. 3 Transhepatic venography (anteroposterior view) shows thrombosis of the proximal superior mesenteric vein (arrow) and patency of portal vein

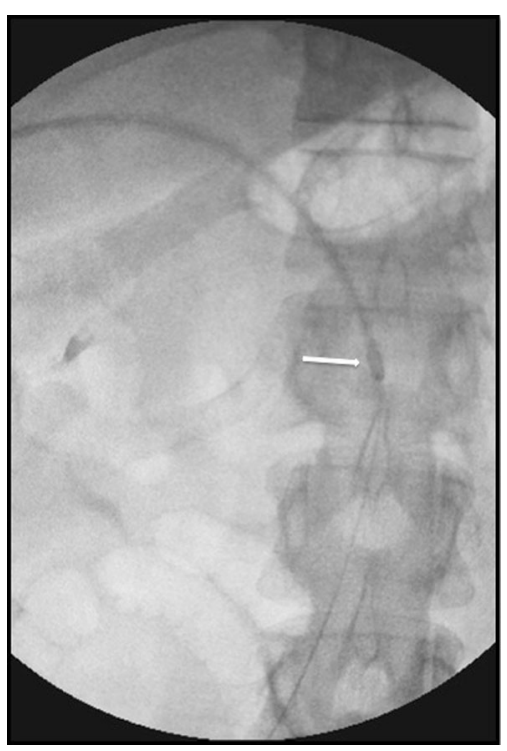

Fig. 4 Advancement of the 10-Fr Aspirex catheter (arrow) into the thrombosed SMV under fluoroscopic guidance

endovascular treatment by means of transcatheter thrombolysis alone may require high dosages and long infusion times, with an increase of up to $60 \%$ in the risk of bleeding and intracranial or gastrointestinal hemorrhage $[11,12]$. Thrombectomy by manual aspiration or by devices which mechanically debulk and aspire the thrombus has been used in the last years and has demonstrated encouraging results [13]. In particular, percutaneous mechanical thrombectomy has proven to be effective in reducing the dosage and the infusion time of thrombolytics $[14,15]$.

Reviewing the PubMed database, 30 reported cases of patients with acute SMV thrombosis who had undergone percutaneous mechanical thrombectomy were found [16-26] (Table 3). In the $93.3 \%$ of cases, the procedure

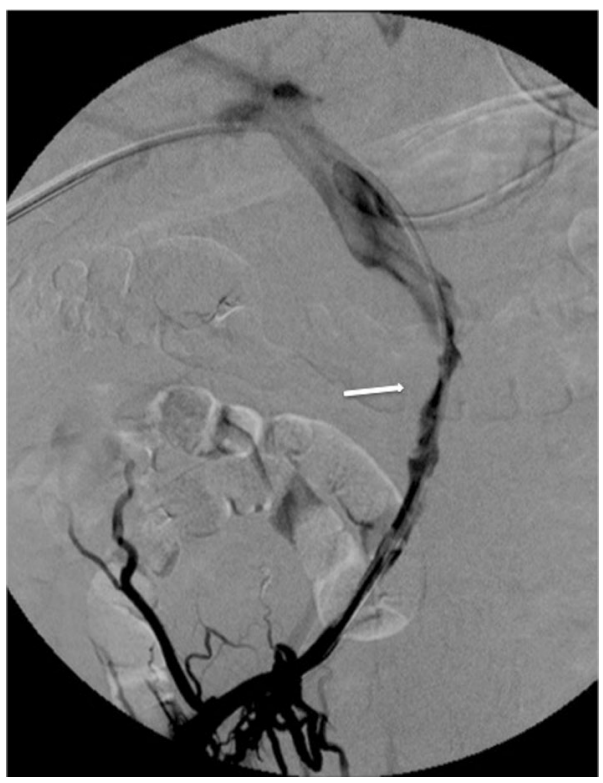

Fig. 5 Control venography immediately after mechanical thrombectomy with Aspirex and before local transcatheter thrombolysis shows partial patency of the SMV with antegrade flow; a narrowing of the main trunk of the vessel caused by residual thrombosis is still evident (arrow)

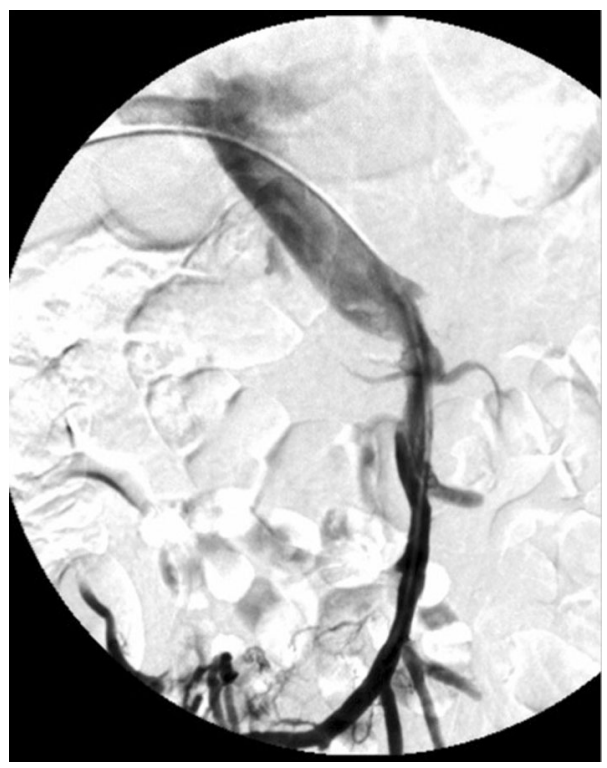

Fig. 6 Control venogram after $48 \mathrm{~h}$ of local thrombolysis demonstrates a significant improvement of flow within the recanalized SMV

was technically successful, flow in the SMV was restored, and abdominal symptoms resolved.

Percutaneous mechanical thrombectomy, either alone or followed by local thrombolysis, was performed in those series using a TJ or a TH approach, in some cases combined with indirect transarterial thrombolytics infusion through the superior mesenteric artery. The transarterial approach is the least efficient because the thrombolytics are 


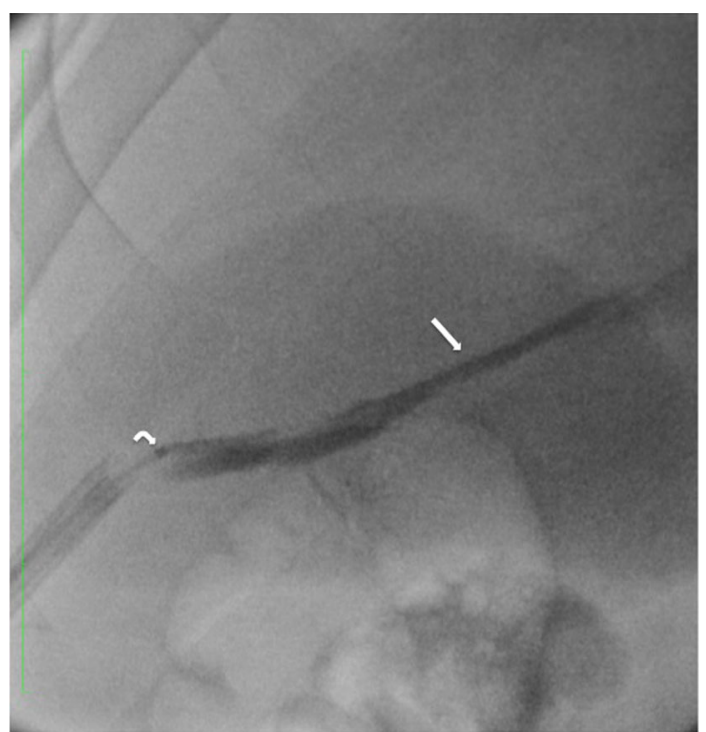

Fig. 7 Tract embolization with Onyx 34: the 11-Fr introducer is partially withdrawn while the radiopaque embolic agent (arrow) is injected through a 2.7 DMSO-compatible microcatheter (curved arrow)

dispersed through the patent arterial branches, without direct vehiculation into the thrombosed vessels. The TIPS approach is invasive and technically challenging, especially in portal vein thrombosis, and it may cause dispersion of the drug into the systemic venous circle. The rationale of this approach is to create a low pressure system which provides a valid outflow for the recanalized vessels in the case of complete extensive thrombosis of the portomesenteric system. A transhepatic ultrasound-guided approach is less invasive, quicker to achieve for operators,

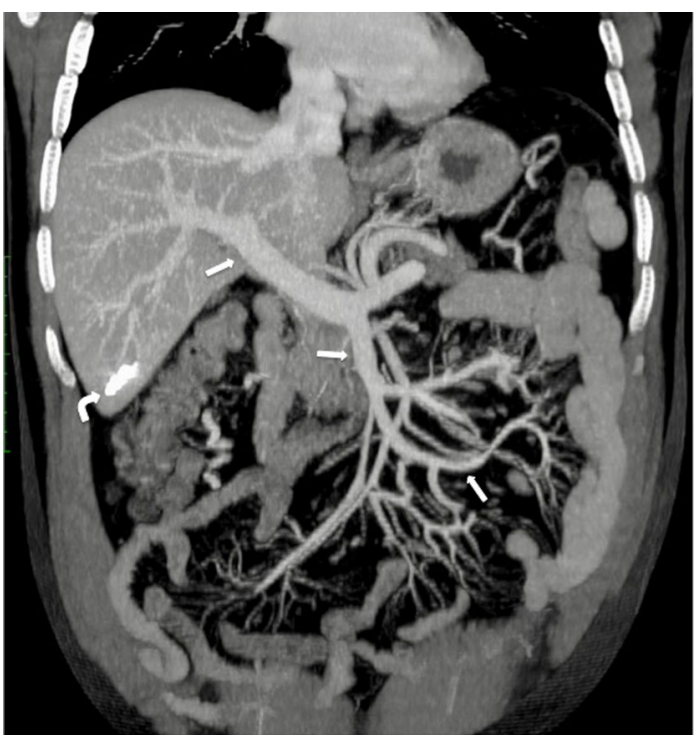

Fig. 9 One-year follow-up CT shows complete recanalization of the SMV and PV (arrow); the hyperdense embolized hepatic tract is still visible within the sixth hepatic segment (curved arrow)

even in the case of puncture of a thrombosed branch, and allows direct, maximized thrombolytic action within the thrombosed vessels. Nevertheless, it requires tract embolization at the end of the treatment, since a large diameter introducer is used (9-11 Fr). It was the first choice in this series for non-cirrhotic patients with patent portal branches representing a potential outflow for the recanalized SMV. In this study, tract embolization was performed using Onyx 34, which was chosen over coils because it allows hemostasis even during ongoing heparinization or thrombolytic therapy.

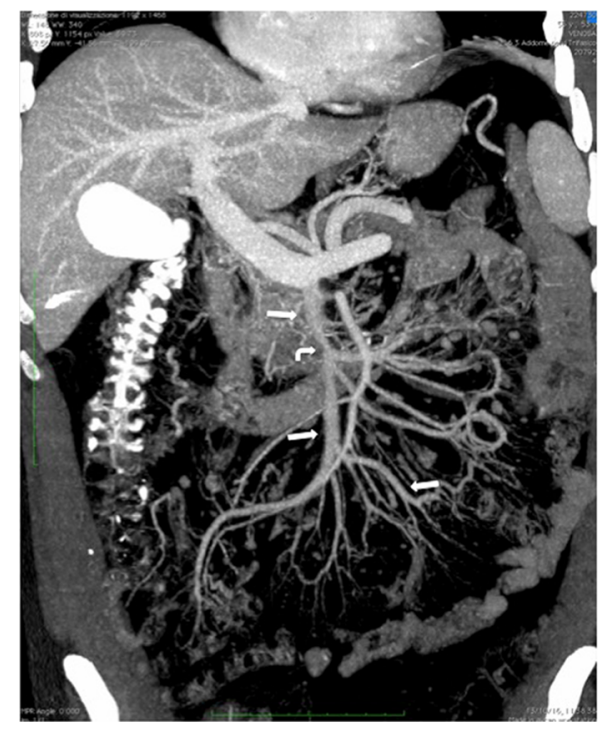

Fig. 8 a Pre-discharge postoperative CT confirms recanalization of both main trunk and side branches of the SMV (arrow); a residual thrombosis is still evident into the SMV lumen (curved arrow). b Pre-

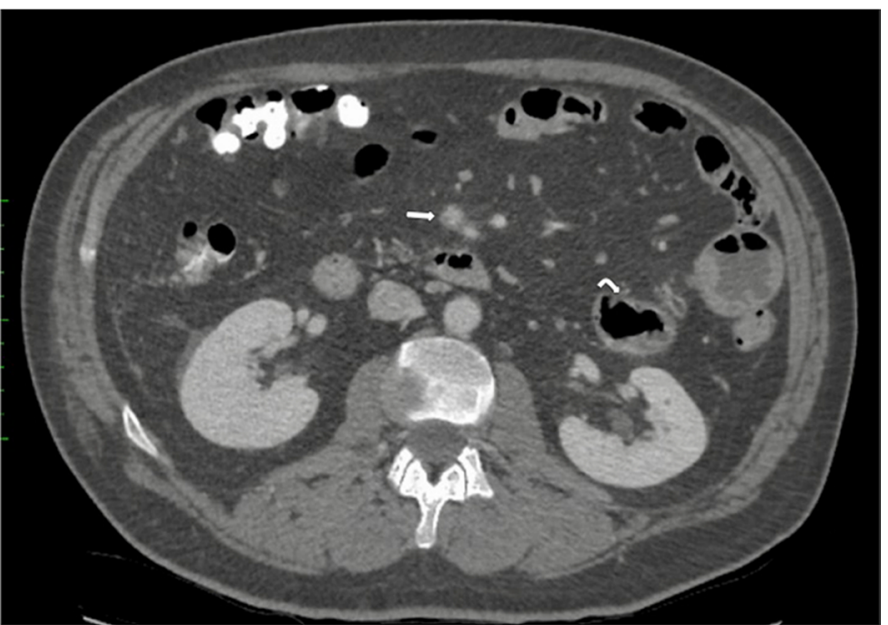

discharge postoperative CT shows resolution of jejunal thickening (curved arrows) and recanalization of the SMV main trunk (arrow) 
Clinical success was obtained in this series in seven out of eight patients, for whom SMV patency was confirmed in FU controls, despite four cases of portal thrombosis recurrence with cavernomatous transformation. It is not clear why portal vein thrombosis recurred, whereas SMV thrombosis did not. A portal cavernoma takes from 6 to 20 days to form after acute thrombosis [27]. In six out of the eight cases, a preexisting cavernomatosis was already present at the moment of PPMT, indicating a potential subacute portal vein thrombosis, which could explain the unusual high rate of rethrombosis; moreover, intravascular ultrasound (IVUS) was not used in this study. Although there is limited evidence of the use of IVUS in the management of portomesenteric thrombosis [28], it has been shown to improve patency outcomes in the iliofemoral DVTs [29]. Therefore, investigations should be carried out as to whether the use of IVUS could also be beneficial in improving patency rates after portomesenteric thrombectomy and thrombolysis. Although cavernomatous transformation is usually considered to be a technical failure of thrombolysis or of mechanical thrombectomy of the portal vein, it was not associated in this study with clinical failure because the cavernoma provided a functional outflow from the recanalized SMV into the intrahepatic circle.

A single case of major bleeding in this series was observed, which was treated with embolization without clinical consequences. No other major adverse events were observed. Intestinal surgical resection after endovascular treatment was not necessary in any of the cases, while Yang [30] in 2015 had described a 50\% resection rate following transcatheter thrombolysis via a combined TJ and SMA approach.

All patients were clinically stable at discharge and have returned to their daily life activities. They are all being treated with anticoagulation therapy and those with portal cavernomatosis continue to be monitored for portal hypertension complications (Figs. 1, 2, 3, 4, 5, 6, 7, 8, 9).

\section{Conclusion}

At present, there is no agreement on the optimal treatment strategy for acute mesenteric venous ischemia, because of the rarity of the condition and the lack of RCTs. In fact, all available data come from single-center small series or case reports. However, results from those series would seem to encourage an early endovascular approach, particularly with percutaneous pharmaco-mechanical thrombectomy, in order to achieve early mesenteric revascularization and avoid surgical resection. According to the findings in this study, treatment of acute SMV thrombosis with PPMT in patients without symptoms and signs of surgical abdomen seemed safe and effective, with a $87.5 \%$ long-term survival rate and a $12.5 \%$ major complication rate.

Conflict of interest The authors declare that they have no conflict of interest.

Open Access This article is distributed under the terms of the Creative Commons Attribution 4.0 International License (http:// creativecommons.org/licenses/by/4.0/), which permits unrestricted use, distribution, and reproduction in any medium, provided you give appropriate credit to the original author(s) and the source, provide a link to the Creative Commons license, and indicate if changes were made.

\section{References}

1. Kumar S, Sarr MG, Kamath PS. Mesenteric venous thrombosis. N Engl J Med. 2001;345:1683-8.

2. Divino CM, Park IS, Angel LP, et al. A retrospective study of diagnosis and management of mesenteric vein thrombosis. Am J Surg. 2001;181:20-3.

3. Kitchens CS. Evolution of our understanding of the pathophysiology of primary mesenteric venous thrombosis. Am J Surg. 1992;163:346-8.

4. Riva N, Donadini MP, Dentali F, et al. Clinical approach to splanchnic vein thrombosis: risk factors and treatment. Thromb Res. 2012;130(Suppl 1):S1-3.

5. Arthurs ZM, Titus J, Bannazadeh M, et al. A comparison of endovascular revascularization with traditional therapy for the treatment of acute mesenteric ischemia. J Vasc Surg. 2011;53(3):698-704.

6. Beaulieu RJ, Arnaoutakis KD, Abularrage CJ. Comparison of open and endovascular treatment of acute mesenteric ischemia. J Vasc Surg. 2014;59(1):159-64.

7. Condat B, Pessione F, Helene Denninger M, et al. Recent portal or mesenteric venous thrombosis: increased recognition and frequent recanalization on anticoagulant therapy. Hepatology. 2000;32:466-70.

8. Hedayati N, Riha GM, Kougias P, et al. Prognostic factors and treatment outcome in mesenteric vein thrombosis. Vasc Endovasc Surg. 2008;42(3):217-24.

9. Abu-Daff S, Abu-Daff N, Al-Shahed M. Mesenteric venous thrombosis and factors associated with mortality: a statistical analysis with five-year follow-up. J Gastrointest Surg. 2009;13:1245-50.

10. Grieshop RJ, Dalsing MC, Cikrit DF, et al. Acute mesenteric venous thrombosis: revisited in a time of diagnostic clarity. Am Surg. 1991;57:573-7.

11. Ouriel K, Gray B, Clair DG, et al. Complications associated with the use of urokinase and recombinant tissue plasminogen activator for catheter-directed peripheral arterial and venous thrombolysis. J Vasc Interv Radiol. 2000;11(3):295-8.

12. Maldonado TS, Blumberg SN, Sheth SU, et al. Mesenteric vein thrombosis can be safely treated with anticoagulation but is associated with significant sequelae of portal hypertension. J Vasc Surg Venous Lymphat Disord. 2016;4:1-7.

13. Stambo GW, Grauer L. Transhepatic portal venous power-pulse spray rheolytic thrombectomy for acute portal vein thrombosis after CT-guided pancreas biopsy. AJR Am J Roentgenol. 2005;184(3 Suppl):S118-9.

14. Nakayama S, Murashima N, Isobe Y. Superior mesenteric venous thrombosis treated by direct aspiration thrombectomy. Hepatogastroenterology. 2008;55(82-83):367-70. 
15. Rossi C, Zambruni A, Ansaloni F, et al. Combined mechanical and pharmacologic thrombolysis for portal vein thrombosis in liver-graft recipients and in candidates for liver transplantation. Transplantation. 2004;78(6):938-40.

16. Zhou W, Choi L, Lin PH, et al. Percutaneous transhepatic thrombectomy and pharmacologic thrombolysis of mesenteric venous thrombosis. Vascular. 2007;15(1):41e45.

17. Rosen MP, Sheiman R. Transhepatic mechanical thrombectomy followed by infusion of TPA into the superior mesenteric artery to treat acute mesenteric vein thrombosis. J Vasc Interv Radiol. 2000;11(2 Pt 1):195-8.

18. Lopera JE, Correa G, Brazzini A, et al. Percutaneous transhepatic treatment of symptomatic mesenteric venous thrombosis. J Vasc Surg. 2002;36(5):1058-61.

19. Kim HS, Patra A, Khan J, et al. Transhepatic catheter-directed thrombectomy and thrombolysis of acute superior mesenteric venous thrombosis. J Vasc Interv Radiol. 2005;16:1685-91.

20. Takahashi N, Kuroki K, Yanaga K. Percutaneous transhepatic mechanical thrombectomy for acute mesenteric venous thrombosis. J Endovasc Ther. 2005;12:508-11.

21. Jun KW, Kim MH, Park KM, et al. Mechanical thrombectomyassisted thrombolysis for acute symptomatic portal and superior mesenteric venous thrombosis. Ann Surg Treat Res. 2014;86(6):334-41.

22. Wassélius J, Sonesson B, Elf $\mathrm{J}$, et al. Treatment of mesenteric vein thrombosis with transjugular mechanical thrombectomy and subsequent simultaneous arterial and venous thrombolysis. J Vasc Surg Venous Lymphat Disord. 2014;2(3):320-3.

23. Lorenz JM, Bennett S, Patel J, et al. Combined pharmacomechanical thrombolysis of complete portomesenteric thrombosis in a liver transplant recipient. Cardiovasc Intervent Radiol. 2014;37:262-6.
24. Song JH, He X, Lou WS, et al. Application of percutaneous AngioJet thrombectomy in patients with acute symptomatic portal and superior mesenteric venous thrombosis. Zhonghua Yi Xue Za Zhi. 2017;97(13):991-5.

25. Syed MI, Gallagher RM, Ahmed RS, et al. t-PA power pulse spray with rheolytic mechanical thrombectomy using cross-sectional image guided portal vein access for single setting treatment of subacute superior mesenteric vein thrombosis. Indian J Radiol Imaging. 2018;28(1):93-8.

26. Kuetting D, Wolter K, Luetkens J, et al. AngioJet-assisted transvenous-transhepatic mechanical thrombectomy in the portal vein. Pol J Radiol. 2018;83:e536-44.

27. De Gaetano AM, Lafortune M, Patriquin H, et al. Cavernous transformation of the portal vein: patterns of intrahepatic and splanchnic collateral circulation detected with Doppler sonography. AJR Am J Roentgenol. 1995;165:1151-5.

28. Farsad K, Fuss C, Kolbeck KJ, et al. Transjugular intrahepatic portosystemic shunt creation using intravascular ultrasound guidance. J Vasc Interv Radiol. 2012;23(12):1594-602.

29. Gillespie D, Johansson M, Glass C. Stent placement after DVT thrombolysis/mechanical thrombectomy? Which patients should be stented and which should not? Endovasc Today. 2009;2009:55-60.

30. Yang S, Liu B, Ding W, et al. Acute superior mesenteric venous thrombosis: transcatheter thrombolysis and aspiration thrombectomy therapy by combined route of superior mesenteric vein and artery in eight patients. Cardiovasc Intervent Radiol. 2015;38:88-99.

Publisher's Note Springer Nature remains neutral with regard to jurisdictional claims in published maps and institutional affiliations. 